\title{
Cataclysms: A New Geology for the Twenty-first Century
}

New York: Columbia University Press, 2017

211 pages

Earth's Catastrophic Past:

\author{
Asteroid Impacts \\ and Mass Extinctions
}

Asteroid impacts and periodic mass extinctions dramatically revise the Lyellian gradualist paradigm

For a century geologists have adhered to the uniformitarian model presented in James Hutton's Theory of the Earth (1794) and documented by Charles Lyell, author of the monumental threevolume Principles of Geology, which went through twelve editions (1830-1875). Hutton sought evidence for a vast geological cycle "without beginning, with no end in sight." Lyell abhorred the catastrophist theories of Abraham Gottlieb Werner, the charismatic German lecturer who traced sedimentary rocks to chemical precipitation following the Noachian flood. Lyell focused on uniform structures and gradual change as the key to the geological past, present, and future. He examined deep layers in sedimentary rock in French and English canyon walls, visited the vast carboniferous deposits at the Joggins Fossil Cliffs in the Bay of Fundy, and identified some ninety distinct eruptions at Mount Aetna-all of which testified to gradual changes over vast periods of time. Additionally, he rejected not only mythical astrological influences but also calamitous asteroid impacts as explanations for geological phenomenon.

Given the power of the gradualist model, even through the revolutionary discoveries of plate tectonics in the 1960s, Michael Rampino's Cataclysms: A New Geology for the Twenty-First Century at first looks like a throwback to a pre-

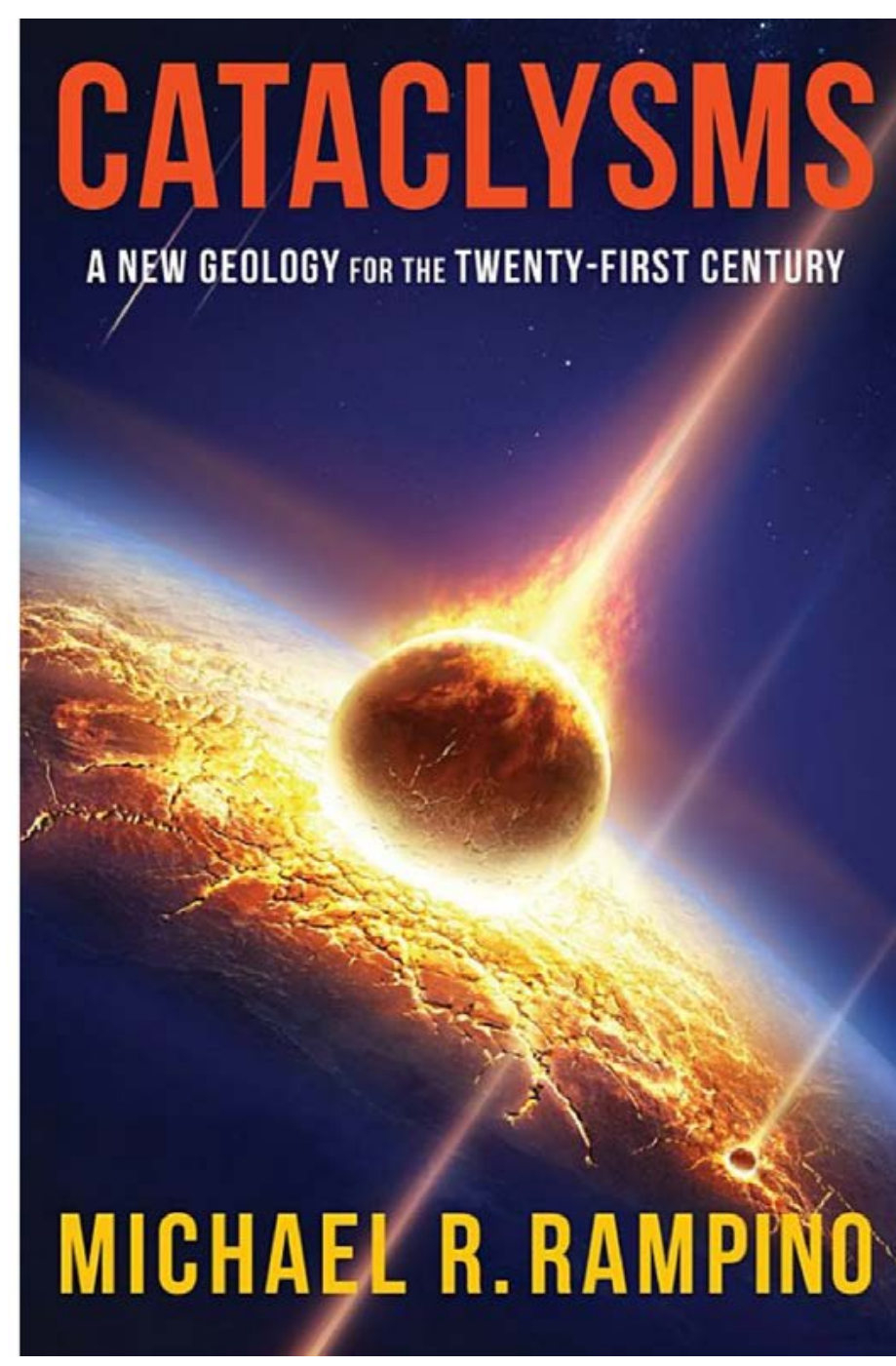

Lyellian era. But this evocative book is rather a solid geological study founded on a wealth of observations gathered over the past forty years and an invitation to reexamine the history of asteroid impacts from a new perspective. While a full theory of cataclysmic geology is still in the making, the outlines are clear. In place of the fabricated catastrophism of William Whiston and myth-based deluge geology of George 
Cuvier and Werner, Rampino has compiled the emerging evidence for regularity in astronomical events affecting the Earth and life, with coherent scientific theory as explanation.

Rampino's starting point is “the Alvarez hypothesis" that emerged with the 1979 discovery by Walter Alvarez of an iridium-rich deposit at the Cretaceous/Paleogene boundary dating to 65 million years ago (mya). Discovered first in the Apennine Mountains in Italy, the same layer was subsequently located at 350 locations worldwide. The tell-tale iridium, an element almost non-existent on Earth, is a certain marker for an extraterrestrial origin. Calculating its source as a 6 to 10 mile diameter asteroid, Alvarez published his theory in Science (1980), linking this cataclysmic impact to the already well-established and dated extinction of the dinosaurs. A decade later the 90-mile diameter crater was located under the Yucatan Peninsula, its center near the town of Chicxulub after which it is named. Dated also at 65 mya, this crater has now been accepted as the smoking gun verifying the Alvarez theory.

The effects of the Chicxulub asteroid are several: besides plunging the world into darkness and destroying the food source of dinosaur predators, it jump-started mammalian and primate ascendancy and ultimately cleared the ground for human emergence. It was thus a chance event to which we probably owe our present existence. But the record of earlier mass extinctions raises the question whether asteroid impacts may explain cataclysmic extinction events in the more extensive history of life.

Rampino has been studying mass extinctions and asteroid impacts for more than thirty years, punctuated with exploratory articles in Science, Nature, Geology, and various astronomy journals. Impact craters more than a few tens of millions years old are often hidden from easy discovery by erosion, sediment accumulation, and forest overgrowth, but the larger ones leave behind welldefined evidence. The Chicxulub impact is marked by shocked quartz scatterings, microtektites on the island of Haiti, boundary sediments on Cuba, and widespread deposits from a $100+$ meter tsunami in northeast Mexico and the Brazos River Valley in Texas. Paleobiology has established extended records of mass extinctions, presumably with additional evidence yet to be discovered. Five are well known: at the end of the Ordovician (444 mya), the late Devonian (372 mya), end of the Permian (252 mya), end of the Triassic (201 mya), and the end of the Cretaceous (66 mya). But noticeable disruptions in fossil inventories have established numerous intermediate extinctions, some contemporaneous with large-impact craters.

The correlation of asteroid impacts with mass extinctions demands multidisciplinary explanation spanning three hitherto discrete disciplines: astronomy, geology, and biology. During the decades of Rampino's researches, the linkage between impacts and extinctions has achieved a measure of clarity. Initially, asteroid arrivals seemed random, but careful correlation indicates impacts clustering at intervals of 26 million years - a repetition that begs for an explanation. It was assumed that asteroids most often originated in the Solar System Oort Cloud beyond the planets, but what periodic event might account for disruption of the Cloud that could send asteroids careening into the inner Solar System? Given the thousands of Near Earth Objects presently orbiting the Sun alongside the relative rarity of life-threatening impacts, it could be assumed that multitudes of dislodged asteroids would be necessary to produce a measurable uptick of collisions.

Various theories have been suggested: a star on an erratic 26-million year orbit or the passage of the Solar System through the galactic arms of the Milky Way; but decisive evidence is lacking. Rampino gives credit to Richard Strothers for pointing out what is called z-oscillation: the Solar System's periodic crossing of the galactic plane. As it circles the galaxy on its 225-million-year orbit, the Solar System crosses the galactic midplane at an 
oblique angle, describing a long arc as it soars away and then is pulled back toward the midplane, then crosses it again. Adopting the highly visual metaphor of a carousel up-and-down motion to illustrate the 26-million-year periodic rhythm of our galactic orbit, Rampino and Strothers tendered the theory that mass extinctions were the result of this orbital cycle. The crossing of the galactic plane necessarily exposes the Solar System for several million years to an increased density of galactic material - other stellar systems, nebulae, possibly concentrations of dark matter. The obvious result would be galactic debris swept into the Solar System and periodic disruptions of the Oort Cloud, leading to increasing numbers of asteroid impacts, with species extinction the result. The theory is set forth in a chapter called "The Shiva Hypothesis," a name adopted in an article by Rampino and his student, Bruce Haggerty, more than twenty years ago: "We decided to call it the Shiva hypothesis, after the Hindu god of destruction and renewal. This matched the idea that extinctions destroy the old world and give rise to a subsequent radiation of new species in the postextinction world."
A geology of cataclysm does not replace the earlier gradualism championed by Lyell and a century of followers. Gradualism and concomitant geological preservation is evident virtually everywhere: stable 3.5 billion-year-old cratonic outcrops are visible in Greenland, Northern Canada, South Africa, and Australia; a 4,000-mile line of seamounts northwest of Hawaii testifies to a slow-moving tectonic plate moving across a hot spot now under the Big Island; layered sedimentary rocks are found on sea bottoms, canyon walls, road cuts, and mountain sides - their folds, tilts, and unconformities providing a historical backdrop for Earth history. Cataclysmic impacts punctuate this underlying gradualist narrative without destroying it; an either/or geology is out of date. As Rampino puts it, "The old battle between gradualist and catastrophist views may have only been shadow boxing. Both types of change seem to have been important in creating the geologic record we see today."
Barry Wood

University of Houston bwood@uh.edu 
